\title{
Gender Differences and Psychopathological Features Associated With Addictive Behaviors in Adolescents
}

\begin{abstract}
Marco Di Nicola ${ }^{1 *}$, Vittoria Rachele Ferri ${ }^{1}$, Lorenzo Moccia', Isabella Panaccione ${ }^{2}$, Annamaria Miriam Strangio ${ }^{1}$, Daniela Tedeschi', Paolo Grandinetti ${ }^{1}$, Antonino Callea ${ }^{3}$, Fabio De-Giorgio ${ }^{4}$, Giovanni Martinotti ${ }^{5}$ and Luigi Janiri ${ }^{1 *}$

'Institute of Psychiatry and Psychology, Fondazione Policlinico Universitario "A. Gemelli", Università Cattolica del Sacro Cuore, Rome, Italy, ${ }^{2}$ NESMOS Department, School of Medicine and Psychology, Sant'Andrea Hospital, Sapienza University of Rome, Rome, Italy, ${ }^{3}$ Department of Human Science, LUMSA University, Rome, Italy, ${ }^{4}$ Section of Legal Medicine, Institute of Public Health, Università Cattolica del Sacro Cuore, Rome, Italy, ${ }^{5}$ Department of Neuroscience and Imaging, Institute of Psychiatry, "G. d'Annunzio" University of Chieti-Pescara, Chieti, Italy
\end{abstract}

Background: The aims of the study were to assess prevalence and gender differences of addictive behaviors (substance- and non-substance-related) in an adolescent popula-

OPEN ACCESS

Edited by:

Angelo Gi Maremmani,

University of Pisa, Italy

Reviewed by:

Mercedes Lovrecic,

National Institute for Public

Health, Slovenia

Adriano Schimmenti,

Kore University of Enna, Italy

${ }^{*}$ Correspondence:

Marco Di Nicola

marcodinicola.md@gmail.com;

Luigi Janiri

luigi.janiri@unicatt.it

Specialty section:

This article was submitted

to Addictive Disorders,

a section of the journal

Frontiers in Psychiatry

Received: 25 August 2017 Accepted: 13 November 2017 Published: 01 December 2017

Citation:

Di Nicola M, Ferri VR, Moccia L,

Panaccione I, Strangio AM,

Tedeschi D, Grandinetti P, Callea A,

De-Giorgio F, Martinotti $G$ and Janiri L (2017) Gender Differences and

Psychopathological Features

Associated With Addictive

Behaviors in Adolescents.

Front. Psychiatry 8:256

doi: 10.3389/fpsyt.2017.00256 tion, and their association with psychopathological features and academic performance.

Material and methods: A sample of high school Italian students $(n=996 ; \mathrm{M}=240$, $F=756)$ was examined using a self-report survey concerning sociodemographic characteristics, cigarette smoking, alcohol and substance use, perceived academic performance, activities, and behaviors (Internet use, gambling, and physical exercising). The Internet Addiction Test, the South Oaks Gambling Screen-revised Adolescent, and the Exercise Addiction Inventory-Short Form were administered to identify problematic behaviors. The Barratt Impulsiveness Scale for Adolescent, the Snaith-Hamilton Pleasure Scale, the Dissociative Experience Scale for Adolescent, and the Toronto Alexithymia Scale were used to investigate psychopathological dimensions.

Results: Frequent alcohol intake and lifetime substances consumption were more common among males. The occurrence of other addictive behaviors was $22.1 \%$ for problematic Internet use $(\mathrm{M}=\mathrm{F}), 9.7 \%$ for at-risk/problematic gambling $(\mathrm{M}>\mathrm{F})$, and $6.2 \%$ for maladaptive physical exercise ( $\mathrm{M}=\mathrm{F}$ ). We also found an association between substance-/ non-substance-related addictive behaviors and psychopathological dimensions. Addictive behaviors were more frequent among students reporting poor school performance.

Conclusion: Our study showed a relevant prevalence of addictive behaviors in a sample of Italian high school students, with specific gender differences. We underlined the cooccurrence of substance and non-substance-related addictive behaviors, and their association with worse school performance. Dissociative proneness, anhedonia, alexithymia, and impulsivity were associated with addictive behaviors in adolescents and might represent vulnerability factors for the development of psychiatric disorders in adulthood. A better understanding of psychopathological features associated with addictive behaviors might be useful for the prevention/early intervention.

Keywords: adolescence, substance use, gambling, Internet, impulsivity, dissociation, alexithymia, school performance 


\section{INTRODUCTION}

Adolescence has far been recognized as a critical developmental period for several reasons, including dramatic physical, cognitive, and psychosocial changes occurring at that time $(1,2)$. Both substance- and non-substance-related addictive behaviors usually onset in adolescence or young adult age and are more prevalent in these age groups than in any others (3). According to the emerging neurobiological model of addiction, neurodevelopmental changes occurring during adolescence lead to an imbalance between emotional (reward motivation) and cognitive processes (executive control) $(3,4)$. In fact, while the limbic system undergoes remarkable remodeling during puberty, prefrontal areas development is not complete until near the age of 25 (5). This neurobiological fragility may contribute in adolescence to a higher risk of developing addictive behaviors (6).

An individual susceptibility constituted by genetic, physiological, and personality characteristics may predispose adolescents to addictive tendencies. However, environmental factors, including early exposure to traumatic life events, familiar history of addictive disorders, increased accessibility to gambling and substances of abuse, and peer influence, have been recognized as risk factors as well $(7,8)$.

The last European School Survey Project on Alcohol and other Drugs (ESPAD) report has extended the scope of the survey to include not only novel substances of abuse but also behavioral addictions, such as problematic Internet use, gaming, and gambling (9). The ESPAD group points out that "the development of patterns of addictive Internet use among children and adolescents needs to be closely monitored and investigated" and that "measures to prevent adolescents from developing problems associated with gambling, such as debt, psychological deficits and social disadvantages, are of high priority."
Distinct psychopathological dimensions have been consistently correlated to the occurrence of addictive disorders in adults (10-13). In the past several years, a growing body of research has started to unravel the complex interaction that occurs between psychopathology and the vulnerability to both substance and non-substance addictive behaviors in adolescents (14-20). Psychopathological factors, including both internalizing and externalizing symptomatology, have been further conceptualized in terms of both predictors and consequences of addictive tendencies in adolescents $(19,21,22)$.

However, there is still limited evidence about occurrence, related features, and impact of addictive behaviors in this population. Therefore, the aims of the study were to assess prevalence, gender differences, psychopathological features, and academic performance associated with addictive behaviors (substanceand non-substance-related) in high school subjects.

\section{MATERIALS AND METHODS}

\section{Procedure}

This cross-sectional study was conducted between 2014 and 2016 in central and southern Italy. From the initial sample of 1,174 students, 178 were not admitted to the study due to missing data on important variables or response polarization. The final sample consisted of 996 subjects $(\mathrm{M}=240, \mathrm{~F}=756)$ (Figure 1).

Anonymity was guaranteed to all participants. The study was approved by the Ethics Committee of Università Cattolica del Sacro Cuore, Rome. It was conducted in accordance with Good Clinical Practice guidelines and the Declaration of Helsinki (1964) and subsequent revisions. All subjects enrolled (or parents/tutors, if they were underage) gave their written informed consent before their inclusion in the study and participated without receiving any form of payment.

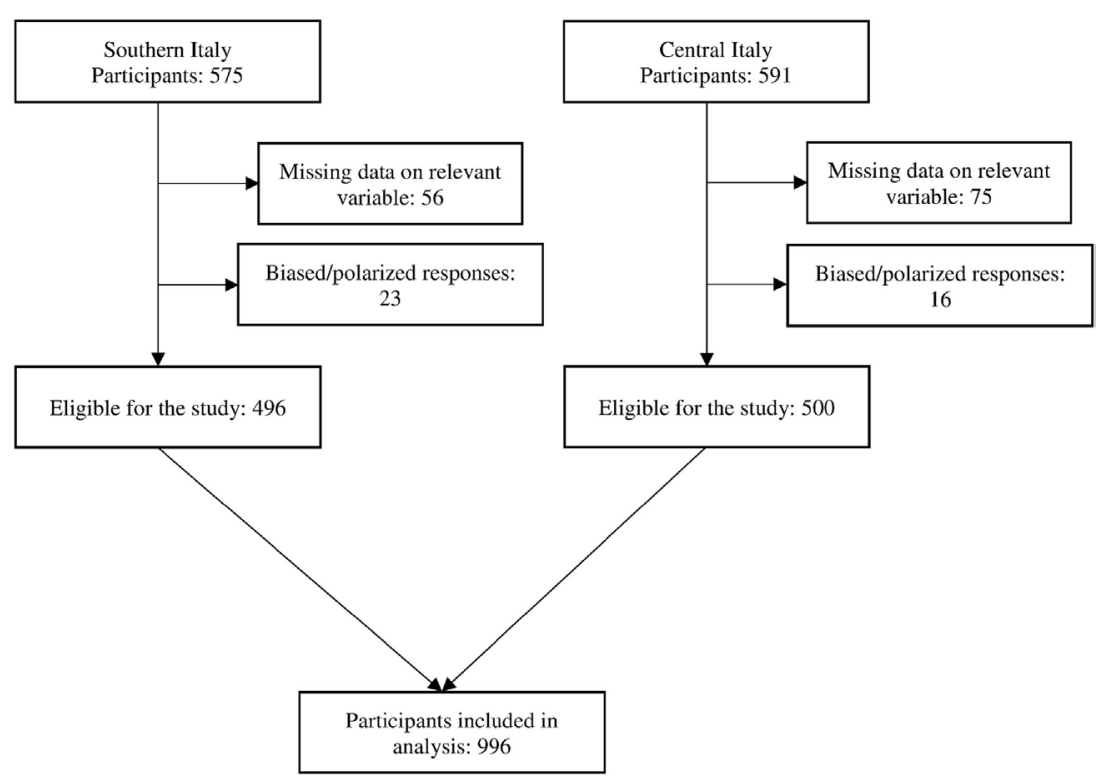

FIGURE 1 | Study flow chart. 
We used a self-report survey assessing sociodemographic characteristics, school grade and performance, parents' marital status and occupation, cigarette smoking, alcohol and substances consumption, and non-substance-related addictive behaviors such as Internet using, gambling, and physical exercising.

To screen for non-substance-related at-risk/problematic behaviors, we administered the Italian versions of:

- Internet Addiction Test [IAT; $(23,24)]$. It consists of 20 items evaluating the impact of Internet use in daily life. Items are rated in a five-point Likert scale (from 1-not at all-to 5-always). The total score distinguishes: average users with a full control of their usage (20-49), subjects with frequent problems because of excessive Internet use (50-79), or having significant problems because of Internet use (80-100).

- South Oaks Gambling Screen-revised Adolescent [SOGS-rA; $(25,26)]$. It is a screening questionnaire for problematic behaviors associated with gambling. The scale refers to the 12 months before the survey and is composed of 12 items investigating the loss of control on the game, the run-up to the losses, interference with daily life, and feelings of guilt related to the game. Scores are used to define three categories of players: no problem (0-1), at-risk (2-3), and problematic $(\geq 4)$.

- Exercise Addiction Inventory-Short Form [EAI-SF; (27)]. It consists of six statements rated on a 5-point Likert scale (from 1-strongly disagree-to 5-strongly agree). Total scores identify three categories of individuals: asymptomatic (0-12), symptomatic (13-23), and at-risk for exercise addiction $(\geq 24)$.

To assess psychopathological dimensions, the Italian version of the following scales was employed:

- Barratt Impulsiveness Scale, Adolescent Version [BIS-11-A; (28)]. It is a 30 -item self-reported questionnaire that targets impulsivity in adolescents. As to authors' recommendations, a single factor model of the scale, including only BIS-11-A total score, was adopted.

- Snaith-Hamilton Pleasure Scale [SHAPS; $(29,30)$ ]. It is a 14-item self-rating scale exploring hedonic responses in common pleasurable situations related to leisure pursuit and interests, eating and drinking, social interactions, and sensory experiences. Previous findings support the use of SHAPS for assessing anhedonia in adolescent populations (31).

- Dissociative Experience Scale for Adolescence [A-DES; $(32,33)]$. It is a self-report screening questionnaire assessing dissociative symptoms in adolescents. It includes four subscales, namely, dissociative amnesia; depersonalization and derealization; absorption and imaginative involvement; and passive influence. A-DES proved to be a valid instrument, with very good internal reliability (34).

- Toronto Alexithymia Scale [TAS-20; $(35,36)]$. It is a 20 -item self-report instrument that assesses alexithymia. It has a three-factor structure, which includes the following subscales: difficulty identifying feelings; difficulty describing feelings; and externally oriented thinking. TAS-20 demonstrated good psychometric properties in adolescent populations (37).

\section{Statistical Analysis}

The statistical package SPSS 21.0 for Mac (SPSS Inc., Chicago, IL, USA) was used for all the analyses. Dichotomous data were compared by chi-square test. Ordinal variables were compared by non-parametric Mann-Whitney $U$ test. Continuous data were expressed as means \pm SD and compared by independent Student's $t$-test. Spearman's rank correlation coefficient was employed to examine the relationship between continuous and ordinal variables. Logistic and linear regressions, through multiple regression method, were performed to identify the association of psychopathological variables with substance-/ non-substance-related addictive behaviors. The statistical significance was set at $p<0.05$.

\section{RESULTS}

\section{Participants and Sociodemographic Characteristics}

Sociodemographic data are reported in Table 1. No differences between male and female students were found, except for parent's marital status $\left(\chi^{2}=8.337, p<0.05\right.$; in males, the percentage of "married" and "separated/divorced" was higher and lower than females, respectively), mother's work $\left(\chi^{2}=19.300, p<0.05\right.$; in males, the percentage of "staff employed" and "deceased/absent/ does not know" was higher, while the percentage of "precarious," "housewife," and "entrepreneur" was lower than females), and school performance $\left(\chi^{2}=17.998 ; p<0.01\right.$; the percentage of "failure" and "poor" was higher for males, while the percentage of "satisfactory," "good," and "excellent" was higher for females).

\section{Substance-Related Addictive Behaviors}

Smoking habit, alcohol intake, and related patterns are described in Table 2. Prevalence of current smoking was $51.1 \%$, with no significant gender differences. Prevalence of current alcohol use was $84.7 \% ; 57.6 \%(\mathrm{M}=64.1 \% ; \mathrm{F}=55.6 \%)$ of the students reported drinking at least once per month, while 30.8\% ( $\mathrm{M}=40 \%$; $\mathrm{F}=27.9 \%$ ) stated taking alcohol once a week or more, with significant gender differences. Frequency of drunkenness episodes was significantly higher in males. No gender differences were found on binge drinking, defined as consuming $\geq 6$ drinks on a single occasion during the past month (38).

Illicit substances consumption and related patterns are reported in Table 3. Comparing the two groups, we found a higher frequency of lifetime illicit substances consumption and multiple substance use in males. Cannabis was the most used drug; 304 subjects ( $84.8 \%$ of substance users) consumed cannabis alone at least once in lifetime and 15 of them (4.8\%) reported a daily consumption. Cannabis use was more frequent among females.

\section{Non-Substance-Related Addictive Behaviors}

Non-substance addictive behaviors and related patterns are reported in Table 4, while IAT, SOGS-rA, and EAI-SF scores are shown in Table 5. 
TABLE 1 | Sociodemographic characteristics.

\begin{tabular}{|c|c|c|c|}
\hline & Total & Male & Female \\
\hline$N$ & 996 & $240(24.1)$ & $756(75.9)$ \\
\hline Age $(M \pm S D)$ & $16.47 \pm 4.85$ & $16.5 \pm 5.61$ & $16.47 \pm 4.58$ \\
\hline \multicolumn{4}{|l|}{ Parent's marital status } \\
\hline Married & $336(67.9)$ & $97(75.2)$ & $239(65.3)$ \\
\hline Separated/divorced & $124(25.1)$ & $22(17.1)$ & $102(27.9)$ \\
\hline Other & $35(7)$ & $10(7.7)$ & $25(6.8)$ \\
\hline \multicolumn{4}{|l|}{ Father's work } \\
\hline Unemployed & $4(0.8)$ & $2(1.6)$ & $2(0.6)$ \\
\hline Precarious & $8(1.7)$ & $2(1.6)$ & $6(1.7)$ \\
\hline Staff employed & $180(37.7)$ & $46(36.2)$ & $134(38.2)$ \\
\hline Professional employee & $203(42.4)$ & $53(41.7)$ & $150(42.7)$ \\
\hline Stay at-home dad & $1(0.2)$ & $1(0.8)$ & $0(0)$ \\
\hline Pensioner & $10(2.1)$ & $2(1.6)$ & $8(2.3)$ \\
\hline Entrepreneur & $52(10.9)$ & $13(10.2)$ & $39(11.1)$ \\
\hline Deceased/absent/does not know & $20(4.2)$ & $8(6.3)$ & $12(3.4)$ \\
\hline \multicolumn{4}{|l|}{ Mother's work } \\
\hline Unemployed & $14(2.9)$ & $4(3.2)$ & $10(2.8)$ \\
\hline Precarious & $17(3.6)$ & $2(1.6)$ & $15(4.3)$ \\
\hline Staff employed & $194(40.6)$ & $57(45.6)$ & $137(38.8)$ \\
\hline Professional employee & $141(29.6)$ & 39 (31.2) & $102(29)$ \\
\hline Housewife & $68(14.3)$ & $10(8)$ & 58 (16.5) \\
\hline Pensioner & $3(0.6)$ & $0(0)$ & $3(0.9)$ \\
\hline Entrepreneur & 17 (3.6) & $2(1.6)$ & $15(4.3)$ \\
\hline Deceased/absent/does not know & $23(4.8)$ & $11(8.8)$ & $12(3.4)$ \\
\hline \multicolumn{4}{|l|}{ School class } \\
\hline 1st & $130(13.1)$ & $37(15.5)$ & $93(12.4)$ \\
\hline 2nd & $85(8.6)$ & $21(8.8)$ & $64(8.5)$ \\
\hline $3 r d$ & 296 (29.9) & 69 (28.9) & 227 (30.2) \\
\hline 4th & $234(23.6)$ & $56(23.4)$ & $178(23.7)$ \\
\hline 5th & $245(24.8)$ & $56(23.4)$ & $189(25.2)$ \\
\hline \multicolumn{4}{|l|}{ School performance } \\
\hline Failure & $95(9.6)$ & $32(13.4)$ & $63(8.4)$ \\
\hline Poor & $193(19.5)$ & 63 (26.3) & $130(17.4)$ \\
\hline Satisfactory & $342(34.6)$ & $72(30.1)$ & $270(36)$ \\
\hline Good & $293(29.7)$ & 58 (24.3) & $235(31.4)$ \\
\hline Excellent & $65(6.6)$ & $14(5.9)$ & $51(6.8)$ \\
\hline
\end{tabular}

The relative percentages are shown in brackets.

$N$, number of study participants; $M$, mean; SD, standard deviation.

$8.2 \%$ of students spent on the Internet more than $6 \mathrm{~h} /$ day; 220 subjects (22.1\%) showed a maladaptive Internet use, according to IAT cutoff ("frequent" and "significant problems"). We found a significant correlation between IAT score and time spent online/day ( rho $=0.381 ; p<0.01$ ), but no gender differences.

$8.3 \%$ of the sample ( $n=74)$ gambled "often" or "always," with higher prevalence among males $(\mathrm{M}=24.8 \%$; $\mathrm{F}=2.9 \%)$. Overall, $9.7 \%$ of the sample $(29.8 \%$ of gamblers) showed a maladaptive gambling behavior, according to SOGS-rA cutoff ("at-risk/problematic" subjects), with significant gender differences $(M=29.9 \% ; F=3.7 \%)$. Moreover, a correlation between frequency of gambling and risk of related problematic behaviors (rho $=0.398 ; p<0.01$ ) was noted. Online gambling was apparently less frequent, with only $3.2 \%$ of the sample reporting having gambled online "often" or "always" with relevant gender differences $(\mathrm{M}=8.9 \% ; \mathrm{F}=1.3 \%)$.

The prevalence of maladaptive physical exercise (EAI-SF cutoff) was $6.2 \%$, with no gender differences.
TABLE 2 | Cigarette smoking, alcohol intake, and related patterns

\begin{tabular}{|c|c|c|c|c|}
\hline & Total & Male & Female & $\begin{array}{c}\text { Comparison } \\
\text { between groups }\end{array}$ \\
\hline \multicolumn{5}{|l|}{$\begin{array}{l}\text { Cigarette } \\
\text { smoking }\end{array}$} \\
\hline No, never & 485 (48.9) & $126(52.9)$ & 359 (47.6) & $U=84,935$ \\
\hline Yes, sometimes & $190(19.2)$ & 39 (16.4) & $151(20.1)$ & $p=0.160$ \\
\hline Yes, often & $58(5.9)$ & $18(7.6)$ & $40(5.3)$ & \\
\hline Yes, everyday & $258(26)$ & $55(23.1)$ & $203(27)$ & \\
\hline \multicolumn{5}{|l|}{ Alcohol intake } \\
\hline Never & $151(15.3)$ & $36(15.2)$ & $115(15.3)$ & $U=76,222.5$ \\
\hline $\begin{array}{l}\text { Less than once } \\
\text { per month }\end{array}$ & $268(27.1)$ & $49(20.7)$ & $219(29.1)$ & $p<0.01$ \\
\hline Once per month & $169(17.1)$ & $31(13.1)$ & $138(18.4)$ & \\
\hline $\begin{array}{l}\text { Several times a } \\
\text { month }\end{array}$ & $96(9.7)$ & $26(11)$ & $70(9.3)$ & \\
\hline Once a week & $169(17.1)$ & $42(17.7)$ & $127(16.8)$ & \\
\hline $\begin{array}{l}\text { Several times } \\
\text { a week }\end{array}$ & $109(11)$ & $40(16.8)$ & $69(9.2)$ & \\
\hline Everyday & $27(2.7)$ & $13(5.5)$ & $14(1.9)$ & \\
\hline \multicolumn{5}{|l|}{ Drunkenness } \\
\hline Never & 287 (35.1) & $60(30.6)$ & 227 (36.6) & $U=58,513.5$ \\
\hline One time & 168 (20.6) & 36 (18.4) & 132 (21.3) & $p<0.05$ \\
\hline Sometimes & $226(27.7)$ & $60(30.6)$ & $166(26.8)$ & \\
\hline Often & 109 (13.4) & $29(14.8)$ & 80 (12.9) & \\
\hline Always & $26(3.2)$ & $11(5.6)$ & $15(2.4)$ & \\
\hline \multicolumn{5}{|l|}{ Binge drinking } \\
\hline No & $745(90.8)$ & 174 (88.3) & 571 (91.5) & $\chi^{2}=1.61$ \\
\hline Yes & $76(9.2)$ & $23(11.7)$ & $53(8.5)$ & $p=0.209$ \\
\hline
\end{tabular}

The relative percentages are shown in brackets.

$U$, Wilcoxon-Mann-Whitney test; $\chi^{2}$, chi-square test; $p, p$ value (statistical significance).

TABLE 3 | Illicit substances consumption and related patterns.

Total Male Female $\begin{gathered}\text { Comparison } \\ \text { between groups }\end{gathered}$

\begin{tabular}{lcccc}
$\begin{array}{l}\text { Lifetime substances } \\
\text { consumption }\end{array}$ & & & & \\
No & $632(63.6)$ & $131(55)$ & $501(66.3)$ & $\chi^{2}=9.855$ \\
Yes & $362(36.4)$ & $107(45)$ & $255(33.7)$ & $p<0.01$ \\
\hline Types of substances & & & & \\
Cannabinoids & $304(84.8)$ & $77(73.3)$ & $227(89.7)$ & $\chi^{2}=20.394$ \\
Stimulants & $2(0.6)$ & $0(0)$ & $2(0.8)$ & $p<0.001$ \\
Other & $2(0.6)$ & $2(1.9)$ & $0(0)$ & \\
More than one & $50(14)$ & $26(24.8)$ & $24(9.5)$ & \\
\hline Frequency of use & & & & \\
Less than once per & $144(45.8)$ & $31(32.6)$ & $113(51.6)$ & $U=8,048$ \\
month & & & & \\
Once per month & $27(8.6)$ & $7(7.4)$ & $20(9.1)$ & $p<0.001$ \\
Several times a month & $42(13.4)$ & $14(14.7)$ & $28(12.8)$ & \\
Once a week & $34(10.8)$ & $11(11.6)$ & $23(10.5)$ & \\
Several times a week & $52(16.6)$ & $26(27.4)$ & $26(11.9)$ & \\
Everyday & $15(4.8)$ & $6(6.3)$ & $9(4.1)$ &
\end{tabular}

The relative percentages are shown in brackets.

$U$, Wilcoxon-Mann-Whitney test; $\chi^{2}$, chi-square test; $p, p$ value (statistical significance).

Finally, we found correlations between IAT, SOGS-rA, and EAI-SF scores (IAT ${ }^{\star}$ SOGS-rA: $r h o=0.174 ; p<0.01$; IAT ${ }^{\star}$ EAI-SF: rho $=0.067 ; p<0.05$; SOGS-rA*EAI-SF: rho $=0.166 ; p<0.01)$. SOGS-rA scores were also correlated to the frequency of alcohol use (rho $=0.200 ; p<0.01$ ) and cigarette smoking ( rho $=0.084$; $p<0.01)$. 


\section{Psychopathological Features Associated With Gender and Addictive Behaviors}

Significant gender differences on psychopathological variables are presented in Table 6. The TAS-20 "Difficulty describing feelings," "Difficulty identifying feelings," and total scores were higher among females.

The A-DES "Absorption and Imaginative Involvement" factor and total scores were higher in females. The A-DES "Dissociative

TABLE 4 | Non-substance addictive behaviors and related patterns.

\begin{tabular}{|c|c|c|c|c|}
\hline & Total & Male & Female & $\begin{array}{c}\text { Comparison } \\
\text { between groups }\end{array}$ \\
\hline \multicolumn{5}{|l|}{ Time online } \\
\hline$<1 \mathrm{~h}$ & $169(19)$ & 47 (21.7) & $122(18.1)$ & $U=81,268.5$ \\
\hline $1-2 \mathrm{~h}$ & 373 (41.8) & 101 (46.5) & 272 (40.4) & $p<0.05$ \\
\hline $3-4 h$ & $196(22)$ & 45 (20.7) & 151 (22.4) & \\
\hline $5-6 h$ & $80(9)$ & $11(5.2)$ & 69 (10.2) & \\
\hline$<8 \mathrm{~h}$ & $28(3.1)$ & $4(1.8)$ & $24(3.6)$ & \\
\hline$>8 \mathrm{~h}$ & $45(5.1)$ & $9(4.1)$ & $36(5.3)$ & \\
\hline \multicolumn{5}{|l|}{$\begin{array}{l}\text { Gambling } \\
\text { online }\end{array}$} \\
\hline Never & 765 (86.7) & 153 (71.9) & 612 (91.6) & $U=56,791.5$ \\
\hline One time & $43(4.9)$ & $16(7.5)$ & $27(4)$ & $p<0.001$ \\
\hline Sometimes & $46(5.2)$ & $25(11.7)$ & $21(3.1)$ & \\
\hline Often & $15(1.7)$ & $9(4.2)$ & $6(0.9)$ & \\
\hline Always & $13(1.5)$ & $10(4.7)$ & $3(0.4)$ & \\
\hline \multicolumn{5}{|l|}{ Gambling } \\
\hline Never & 589 (65.7) & $74(34.1)$ & 515 (75.8) & $U=57,258$ \\
\hline One time & $69(7.7)$ & $24(11.1)$ & 45 (6.6) & $p<0.001$ \\
\hline Sometimes & 164 (18.3) & $65(30)$ & 99 (14.7) & \\
\hline Often & $50(5.6)$ & 37 (17.1) & $13(1.9)$ & \\
\hline Always & $24(2.7)$ & $17(7.7)$ & 7 (1) & \\
\hline
\end{tabular}

The relative percentages are shown in brackets.

$U$, Wilcoxon-Mann-Whitney test; $p, p$ value (statistical significance).
Amnesia" factor score was higher in binge drinkers $(t=-3.228$; $p<0.01)$ and was associated with alcohol consumption $($ rho $=0.232 ; p<0.01)$ and drunkenness episodes (rho $=0.223$; $p<0.01)$.

No gender difference on BIS-11-A total score was observed. Binge drinkers obtained higher BIS-11-A total scores $(t=-4.325$; $p<0.001)$. BIS-11-A total score was also associated with drunkenness episodes (rho $=0.252 ; p<0.01)$ and cigarette smoking $($ rho $=0.267 ; p<0.01)$.

Logistic regression analysis showed that binge drinking was associated with TAS-20 "Difficulty Identifying Feelings" $(b=1.072 ; p<0.001)$ and "Difficulty Describing Feelings" factors $(b=0.945 ; p<0.01)$, with A-DES "Dissociative Amnesia" factor $(b=1.107 ; p<0.001)$ and total scores $(b=0.986 ; p<0.001)$, and with BIS-11-A total score $(b=1.036 ; p<0.001)$.

Multiple regression analysis also highlighted that problematic Internet use (as to IAT) was related to both A-DES "Absorption and Imaginative Involvement" factor $(b=0.323 ; p<0.001)$ and total scores $(b=0.111 ; p<0.05)$, and with TAS-20 $(b=0.193$; $p<0.001)$ and BIS-11-A $(b=0.236 ; p<0.001)$ total scores $\left(R^{2}=0.176\right)$. Maladaptive gambling behavior (as to SOGS-rA) was associated with SHAPS total $(b=0.182 ; p<0.001)$ and A-DES "Dissociative Amnesia" factor $(b=0.279 ; p<0.001)$ scores $\left(R^{2}=0.054\right)$. Problematic physical exercise was associated with TAS-20 $(b=0.149 ; p<0.01)$, A-DES $(b=0.155 ; p<0.01)$ and, inversely, with BIS-11-A $(b=-0.209 ; p<0.001)$ total scores $\left(R^{2}=0.064\right)$.

\section{Academic Performance}

$40.9 \%(n=148)$ of students with lifetime history of substance consumption $(n=362)$ reported failure/poor academic performance compared to $23.4 \%(n=148)$ of subjects without it $(n=632)\left(\chi^{2}=38.31 ; p<0.001\right)$. Negative correlations between

TABLE 5 | Gender differences on IAT, SOGS-rA, and EAI-SF scores.

\begin{tabular}{|c|c|c|c|c|}
\hline & Total & Male & Female & Comparison between groups \\
\hline IAT scores $(\mathrm{M} \pm \mathrm{SD})$ & $40.93 \pm 13.40$ & $41.26 \pm 13.64$ & $40.83 \pm 13.34$ & $\begin{array}{l}t=0.416 \\
p=0.678\end{array}$ \\
\hline \multicolumn{5}{|l|}{ IAT results } \\
\hline Average users & $776(77.9)$ & $179(74.3)$ & 597 (78.9) & $U=79,777$ \\
\hline Frequent problems & $212(21.3)$ & $61(25.7)$ & $151(20)$ & $p=0.199$ \\
\hline Significant problems & $8(0.8)$ & $0(0)$ & $8(1.1)$ & \\
\hline SOGS-rA scores $(M \pm S D)$ & $0.46 \pm 1.40$ & $1.35 \pm 2.21$ & $0.19 \pm 0.89$ & $\begin{array}{c}t=11.478 \\
p<0.001\end{array}$ \\
\hline \multicolumn{5}{|l|}{ SOGS-rA results } \\
\hline No problem & 858 (90.3) & $155(70.1)$ & 703 (96.3) & $U=59,402.5$ \\
\hline At-risk & $47(4.9)$ & 30 (13.6) & $17(2.3)$ & $p<0.001$ \\
\hline Problematic & $46(4.8)$ & $36(16.3)$ & $10(1.4)$ & \\
\hline EAl-SF scores $(M \pm S D)$ & $13.18 \pm 5.71$ & $14.53 \pm 5.52$ & $12.76 \pm 5.71$ & $\begin{array}{l}t=4.151 \\
p<0.001\end{array}$ \\
\hline \multicolumn{5}{|l|}{ EAI-SF results } \\
\hline Asymptomatic individual & $509(52.4)$ & $91(39.1)$ & $418(56.6)$ & $U=71,654$ \\
\hline Symptomatic individual & $402(41.4)$ & $127(54.5)$ & 275 (37.3) & $p<0.001$ \\
\hline At-risk for exercise addiction & $60(6.2)$ & $15(6.4)$ & $45(6.1)$ & \\
\hline
\end{tabular}

The relative percentages are shown in brackets.

IAT, Internet Addiction Test; SOGS-rA, South Oaks Gambling Screen-revised Adolescent; EAI-SF, Exercise Addiction Inventory-Short Form; M, mean; SD, standard deviation; $U$, Wilcoxon-Mann-Whitney test; $t$, Student's $t$-test; $p$, $p$ value (statistical significance). 
TABLE 6 | Gender differences on psychopathological features.

\begin{tabular}{|c|c|c|c|c|}
\hline & Total & Male & Female & Comparison between groups \\
\hline TAS-20 total score & $51.72 \pm 11.53$ & $49.37 \pm 12.11$ & $52.43 \pm 11.26$ & $t=-3.485 ; p<0.01$ \\
\hline Difficulty describing feelings & $16.28 \pm 6.1$ & $14.61 \pm 6.03$ & $16.79 \pm 6.04$ & $t=4.711 ; p<0.001$ \\
\hline Difficulty identifying feelings & $15.5 \pm 6.54$ & $13.68 \pm 5.73$ & $16.05 \pm 6.67$ & $t=-4.773 ; p<0.001$ \\
\hline Externally oriented thinking & $19.98 \pm 5.49$ & $20.86 \pm 5.1$ & $19.72 \pm 5.61$ & $t=-2.737 ; p<0.01$ \\
\hline A-DES total score & $1.99 \pm 1.14$ & $1.29 \pm 1.26$ & $2.23 \pm 1.07$ & $t=-2.197 ; p<0.05$ \\
\hline Dissociative amnesia & $1.85 \pm 1.07$ & $1.83 \pm 1.28$ & $1.86 \pm 0.99$ & $t=-0.232 ; p=0.817$ \\
\hline Absorption and imaginative involvement & $2.69 \pm 0.19$ & $2.09 \pm 2.20$ & $2.91 \pm 2.3$ & $t=-3.515 ; p<0.001$ \\
\hline Depersonalization and derealization & $1.61 \pm 0.92$ & $1.48 \pm 0.93$ & $1.66 \pm 0.91$ & $t=-1.976 ; p=0.059$ \\
\hline Passive influence & $1.95 \pm 1.16$ & $1.92 \pm 1.17$ & $1.99 \pm 1.15$ & $t=-2.654 ; p=0.061$ \\
\hline SHAPS total score & $1.23 \pm 1.79$ & $1.64 \pm 2.20$ & $1.10 \pm 1.62$ & $t=3.986 ; p<0.001$ \\
\hline BIS-11-A total score & $64.09 \pm 9.99$ & $63.81 \pm 11.41$ & $64.09 \pm 9.99$ & $t=-0.493 ; p=0.622$ \\
\hline
\end{tabular}

Values are expressed as mean \pm standard deviation $(M \pm S D)$.

TAS-20, Toronto Alexithymia Scale; A-DES, Dissociative Experience Scale for Adolescence; SHAPS, Snaith-Hamilton Pleasure Scale; BIS-11-A, Barratt Impulsiveness Scale for Adolescents; $t$, Student's t-test; $p, p$ value.

perceived school performance, maladaptive Internet use (IAT total score; rho $=-0.208 ; p<0.01)$, and impulsivity traits (BIS-11-A total score; rho $=-0.335 ; p<0.01$ ) were also found.

\section{DISCUSSION}

Our findings confirm a relevant prevalence of substance- and non-substance addictive behaviors among high school Italian students. In line with previous studies, the percentage of subjects who reported drinking several times a week/everyday was $13.7 \%$, with a predominance of males $(9,39,40)$.

Worryingly, our data revealed that $9.2 \%$ of students experimented binge drinking as a usual pattern of alcohol consumption, with no gender differences. A similar scenario emerged from the ESPAD study, in which 13\% of the students reported "intoxication in the last 30 days," with a slight preponderance of males (9).

Due to its cognitive and psychomotor effects on reaction time and coordination (41), alcohol use significantly contributes to the incidence of injuries, accidents, and other traumas, particularly among younger age groups. For alcohol-related injuries, binge drinking has been found to be a major factor (42).

Adolescence is a critical period for brain development, and the adolescent brain is particularly sensitive to the effect of alcohol and other psychoactive substances. Studies suggest that the specific consumption pattern of alternating alcohol intoxications and abstinent episodes, which is linked to excitotoxic cell death during withdrawal, may be deleterious for the nervous system (43). Binge drinking may therefore result in long-term changes in brain functioning.

Binge drinking is also associated with both acute (i.e., hangovers, blackouts, memory loss, etc.) and long-term clinical consequences, including the progression to established alcohol use disorders (44). Furthermore, binge drinking may lead to unprotected sexual activity or sexual assaults (45).

In our study, the use of both alcohol and illicit drugs coexisted in $33.6 \%$ of participants and, consistently with previous reports, was more common among males (9, 39, 40). The prevalence of substance use was higher than described by ESPAD (36.4 vs. $28 \%$ ) (9), with cannabinoids being the most frequently consumed substances (84.8\%). In contrast to previous findings, in our sample lifetime cannabinoids consumption was higher among females (46). As recently pointed out, gender difference in cannabis use has decreased over time, and this gap is progressively narrowing (47). Worryingly, studies on effects of cannabinoid exposure during adolescence in both humans and preclinical models suggest that females are more vulnerable to be deleteriously affected by these substances (48).

Few data are still available on the prevalence of nonsubstance addictive behaviors among adolescents. $22.1 \%$ of study subjects showed a maladaptive Internet use that was related to the number of hours/day spent online rather than the number of days/week (49). In our sample, the prevalence of subjects with problematic use of Internet is higher than reported by previous European studies $(50,51)$. This finding might be related to the increase of Internet use over the years and to progressively younger age of children currently accessing the Web (52).

We found that $9.7 \%$ of students were at risk for problematic gambling, showing a correlation with the frequency of gambling. The prevalence of problematic gambling was higher than observed in other European countries $(53,54)$.

The occurrence of maladaptive physical exercise was $6.2 \%$. A research conducted among young adults by Meulemans and colleagues (55) stated that $3.3 \%$ of students were characterized as "at-risk" for exercise addiction, and $51.5 \%$ as "non-dependentsymptomatic," while another study reported a prevalence of exercise addiction ranging from 23.8 to $26.2 \%$ (56).

No gender differences were found for problematic Internet use $(\mathrm{M}=25.7 \% ; \mathrm{F}=21.1 \%)$ and physical exercise $(\mathrm{M}=6.4 \%$; $\mathrm{F}=6.1 \%$ ), while problematic gambling, as previously observed in other studies, was significantly more common in males $(\mathrm{M}=29.9 \% ; \mathrm{F}=3.7 \%)(9,57,58)$.

Interestingly, problematic Internet use, gambling, and physical exercise were related with the frequency of alcohol consumption. The cooccurrence of alcohol/substances use and addictive behaviors, such as Internet use and gambling, have been already 
observed in adults $(59,60)$ and adolescents $(56,61-63)$. This cooccurrence may be explained by common biological factors and/or personality traits as impulsivity and sensation/novelty seeking (64).

Specific psychopathological features might also contribute to the development of distinct addictive behaviors, and possibly to an increased proneness for multiple cooccurring addictions (59). Accordingly, in our study, dissociative liability, anhedonia, alexithymia, and impulsivity levels have been found to be associated with the occurrence of addictive behaviors in adolescents. Of note, we observed that dissociative symptoms seem to be a common feature across diverse types of maladaptive behaviors (i.e., binge drinking, problematic gambling, Internet use, and physical exercise) consistently with previous reports (65-67). Dissociation is usually conceptualized as a lack of the integrative functions of memory, consciousness, and identity and is often related to traumatic experiences. However, non-pathological dissociative symptoms are quite common in the general population and several studies suggest that dissociation cannot be simply considered as a learned strategy to decrease emotional engagement (68), but it can be rather regarded as a structural, sometimes dysfunctional, emotion-regulation strategy $(69,70)$. In fact, dissociative proneness is related to deficits in the ability to symbolize and mentalize affective experiences (71), and elevated levels of dissociation are related to cognitive impairments in healthy subjects (72).

Taken together, the propensity to experience dissociative states, the inability to express and understand self-affects, the tendency to act rapidly and without reflexive thinking, along with a blunted capacity of experiencing pleasure in everyday life may thus be thought as vulnerability factors for addictive behaviors in adolescence. These psychopathological features may reflect a more general individual incapacity to regulate [i.e., to mentalize; (73)] affects induced by stressful events which ultimately leads to repetitive, dysfunctional behavioral patterns $(74,75)$. Consistently with theories that recognize an influence of addictive behaviors on cognitive and affective capacities of adolescents, both substance and behavioral addictions have been recently conceptualized as specific forms of maladaptive self-regulatory strategies $(76,77)$. In line with a unifying psychological perspective of addictions, the particularly intense and rigid relationship between the individual and his substance, or activity of choice, contributes to the development of the addictive process (78).

Finally, as shown in our and previous studies, specific psychopathological features seem to play a significant role in the development of both substance and non-substance-related addictive behaviors. Therefore, it is possible to speculate that behavioral addictions could be considered as an expression of an individual underlying psychopathological fragility, rather than symptoms of excessive involvement in maladaptive activities per se (79).

Among young people, academic or educational impairment owing to missed classes, falling behind on work, and lower grades was associated with binge drinking (80). Our study revealed that the frequency of subjects reporting failure/ poor school performance was almost two times higher among students with a lifetime substance consumption. Similarly, as recently described in other countries $(81,82)$, problematic Internet use and gambling were more common in students who reported failure/poor school performance. Therefore, it is possible to state that both substance and non-substance addictive behaviors might negatively influence the educational path of adolescents.

To the best of our knowledge, this is the first study investigating the association of substance- and non-substance-related addictive behaviors with distinct psychopathological dimensions and perceived poor academic performance in a sample of Italian adolescents.

However, this study presents few limitations, such as the relatively small sample size, the predominance of females, and the cross-sectional nature that precluded the ability to identify the chronological order of the onset of different addictive behaviors.

Given the negative impact on adolescents' quality of life, and the increased risk for violent/aggressive behaviors (83) as well as for addictive and other psychiatric disorders in adulthood (84), early recognition of alcohol/substance use, binge drinking, and addictive behaviors becomes crucial. Further studies are necessary to better define psychopathological correlates of addictive behaviors in adolescents, to clarify, prevent, and curb this phenomenon.

\section{ETHICS STATEMENT}

This study was carried out in accordance with the recommendations of Good Clinical Practice guidelines and the Declaration of Helsinki (1964) and subsequent revisions. All subjects (or parents/tutors, if they were underage) gave written informed consent. The protocol was approved by the Ethics Committee of Università Cattolica del Sacro Cuore, Rome, Italy.

\section{AUTHOR CONTRIBUTIONS}

$\mathrm{MN}$ and LJ were primarily responsible for study design and contributed to data interpretation and article writing. AS and PG performed data collection and contributed to data interpretation. VF and DT were involved in data entry and database management. AC performed statistical analysis. GM and FD-G were involved in data interpretation. VF, LM, and IP contributed to data interpretation and article writing. All authors personally revised and approved the final version of the manuscript.

\section{ACKNOWLEDGMENTS}

Authors would like to thank Dr. Salvatore Di Pietro, Dr. Stefania Fiore, Dr. Lorenzo Trivellini, and Dr. Ilaria Vota for their contribution in data entry. 


\section{REFERENCES}

1. Arain M, Haque M, Johal L, Mathur P, Nel W, Rais A, et al. Maturation of the adolescent brain. Neuropsychiatr Dis Treat (2013) 9:449-61. doi:10.2147/ NDT.S39776

2. Giedd JN. Adolescent neuroscience of addiction: a new era. Dev Cogn Neurosci (2015) 16:192-3. doi:10.1016/j.dcn.2015.11.002

3. Hammond CJ, Mayes LC, Potenza MN. Neurobiology of adolescent substance use and addictive behaviors: prevention and treatment implications. Adolesc Med State Art Rev (2014) 25:15-32.

4. Sturman DA, Moghaddam B. The neurobiology of adolescence: changes in brain architecture, functional dynamics, and behavioral tendencies. Neurosci Biobehav Rev (2011) 35:1704-12. doi:10.1016/j.neubiorev.2011. 04.003

5. Somerville LH, Jones RM, Casey BJ. A time of change: behavioral and neural correlates of adolescent sensitivity to appetitive and aversive environmental cues. Brain Cogn (2010) 72:124-33. doi:10.1016/j.bandc.2009. 07.003

6. Oman RF, Vesely S, Aspy CB, McLeroy KR, Rodine S, Marshall L. The potential protective effect of youth assets on adolescent alcohol and drug use. Am J Public Health (2004) 94:1425-30. doi:10.2105/AJPH.94.8.1425

7. Brezing C, Derevensky JL, Potenza MN. Non-substance-addictive behaviors in youth: pathological gambling and problematic Internet use. Child Adolesc Psychiatr Clin N Am (2010) 19:625-41. doi:10.1016/j.chc.2010.03.012

8. Gray KM, Squeglia LM. Research review: what have we learned about adolescent substance use? J Child Psychol Psychiatry (2017). doi:10.1111/ jcpp. 12783

9. The ESPAD Group. ESPAD Report 2015: Results from the European School Survey Project on Alcohol and Other Drugs. Lisbon: European Monitoring Centre for Drugs and Drug Addiction (EMCDDA) (2016). Available from: http:// www.emcdda.europa.eu/publications/joint-publications/emcdda-espadreport_en

10. Martinotti G, Di Nicola M, Tedeschi D, Cundari S, Janiri L. Empathy ability is impaired in alcohol-dependent patients. Am J Addict (2009) 18:157-61. doi:10.1080/10550490802544391

11. Hatzigiakoumis DS, Martinotti G, Giannantonio MD, Janiri L. Anhedonia and substance dependence: clinical correlates and treatment options. Front Psychiatry (2011) 2:10. doi:10.3389/fpsyt.2011.00010

12. Lee TK, Roh S, Han JH, Park SJ, Soh MA, Han DH, et al. The relationship of problematic Internet use with dissociation among South Korean Internet users. Psychiatry Res (2016) 241:66-71. doi:10.1016/j.psychres.2016.04.109

13. Moccia L, Pettorruso M, De Crescenzo F, De Risio L, di Nuzzo L, Martinotti G, et al. Neural correlates of cognitive control in gambling disorder: a systematic review of fMRI studies. Neurosci Biobehav Rev (2017) 78:104-16. doi:10.1016/j. neubiorev.2017.04.025

14. Du X, Qi X, Yang Y, Du G, Gao P, Zhang Y, et al. Altered structural correlates of impulsivity in adolescents with Internet gaming disorder. Front Hum Neurosci (2016) 10:4. doi:10.3389/fnhum.2016.00004

15. Dorard G, Bungener C, Phan O, Edel Y, Corcos M, Berthoz S. Is alexithymia related to cannabis use disorder? Results from a case-control study in outpatient adolescent cannabis abusers. J Psychosom Res (2017) 95:74-80. doi:10.1016/j.jpsychores.2017.02.012

16. Schimmenti A, Passanisi A, Caretti V, La Marca L, Granieri A, Iacolino C, et al. Traumatic experiences, alexithymia, and Internet addiction symptoms among late adolescents: a moderated mediation analysis. Addict Behav (2017) 64:314-20. doi:10.1016/j.addbeh.2015.11.002

17. Morrison $\mathrm{CM}$, Gore $\mathrm{H}$. The relationship between excessive Internet use and depression: a questionnaire-based study of 1,319 young people and adults. Psychopathology (2010) 43:121-6. doi:10.1159/000277001

18. Kandri TA, Bonotis KS, Floros GD, Zafiropoulou MM. Alexithymia components in excessive Internet users: a multi-factorial analysis. Psychiatry Res (2014) 15:348-55. doi:10.1016/j.psychres.2014.07.066

19. Kaess M, Durkee T, Brunner R, Carli V, Parzer P, Wasserman C, et al. Pathological Internet use among European adolescents: psychopathology and self-destructive behaviours. Eur Child Adolesc Psychiatry (2014) 23:1093-102. doi:10.1007/s00787-014-0562-7
20. Müller KW, Janikian M, Dreier M, Wölfling K, Beutel ME, Tzavara C, et al Regular gaming behavior and Internet gaming disorder in European adolescents: results from a cross-national representative survey of prevalence, predictors, and psychopathological correlates. Eur Child Adolesc Psychiatry (2015) 24:565-74. doi:10.1007/s00787-014-0611-2

21. Castellanos-Ryan N, Struve M, Whelan R, Banaschewski T, Barker GJ, Bokde AL, et al. Neural and cognitive correlates of the common and specific variance across externalizing problems in young adolescence. Am J Psychiatry (2014) 171:1310-9. doi:10.1176/appi.ajp.2014.13111499

22. Wartberg L, Brunner R, Kriston L, Durkee T, Parzer P, Fischer-Waldschmidt G, et al. Psychopathological factors associated with problematic alcohol and problematic Internet use in a sample of adolescents in Germany. Psychiatry Res (2016) 240:272-7. doi:10.1016/j.psychres.2016.04.057

23. Young KS. Internet addiction: the emergence of a new clinical disorder. Cyberpsychol Behav (2009) 1:237-44. doi:10.1089/cpb.1998.1.237

24. Fioravanti G, Casale S. Evaluation of the psychometric properties of the Italian Internet Addiction Test. Cyberpsychol Behav Soc Netw (2015) 18:120-8. doi:10.1089/cyber.2014.0493

25. Winters KC, Stinchfield RD, Kim LG. Monitoring adolescent gambling in Minnesota. J Gambl Stud (1995) 11:165-83. doi:10.1007/BF02107113

26. Colasante E, Gori M, Bastiani L, Scalese M, Siciliano V, Molinaro S. Italian adolescent gambling behaviour: psychometric evaluation of the South Oaks Gambling Screen: Revised for Adolescents (SOGS-RA) among a sample of Italian students. J Gambl Stud (2014) 30:789-801. doi:10.1007/s10899013-9385-6

27. Griffiths MD, Szabo A, Terry A. The exercise addiction inventory: a quick and easy screening tool for health practitioners. Br J Sports Med (2005) 39:e30. doi:10.1136/bjsm.2004.017020

28. Fossati A, Barratt ES, Acquarini E, Di Ceglie A. Psychometric properties of an adolescent version of the Barratt Impulsiveness Scale-11 for a sample of Italian high school students. Percept Mot Skills (2002) 95:621-35. doi:10.2466/ pms.2002.95.2.621

29. Snaith RP, Hamilton M, Morley S, Humayan A, Hargreaves D, Trigwell P. A scale for the assessment of hedonic tone the Snaith-Hamilton Pleasure Scale. Br J Psychiatry (1995) 167:99-103. doi:10.1192/bjp.167.1.99

30. Santangelo G, Morgante L, Savica R, Marconi R, Grasso L, Antonini A, et al. Anhedonia and cognitive impairment in Parkinson's disease: Italian validation of the Snaith-Hamilton Pleasure Scale and its application in the clinical routine practice during the PRIAMO study. Parkinsonism Relat Disord (2009) 15:576-81. doi:10.1016/j.parkreldis.2009.02.004

31. Leventhal AM, Unger JB, Audrain-McGovern J, Sussman S, Volk HE, Strong DR. Measuring anhedonia in adolescents: a psychometric analysis. J Pers Assess (2015) 97:506-14. doi:10.1080/00223891.2015.1029072

32. Armstrong JG, Putnam FW, Carlson EB, Libero DZ, Smith SR. Development and validation of a measure of adolescent dissociation: the Adolescent Dissociative Experiences Scale. J Nerv Ment Dis (1997) 185:91-7. doi:10.1097/ 00005053-199708000-00003

33. De Pasquale C, Sciacca F, Hichy Z. Validation of the Italian version of the Dissociative Experience Scale for Adolescents and Young Adults. Ann Gen Psychiatry (2016) 15:31. doi:10.1186/s12991-016-0120-4

34. Schimmenti A. Psychometric properties of the Adolescent Dissociative Experiences Scale in a sample of Italian adolescents. J Trauma Dissociation (2016) 17:244-57. doi:10.1080/15299732.2015.1064507

35. Bagby RM, Taylor GJ, Parker JD. The Twenty-Item Toronto Alexithymia Scale-II. Convergent discriminant, and concurrent validity. J Psychosom Res (1994) 38:33-40. doi:10.1016/0022-3999(94)90006-X

36. Bressi C, Taylor G, Parker J, Bressi S, Brambilla V, Aguglia E, et al. Cross validation of the factor structure of the 20-Item Toronto Alexithymia Scale: an Italian multicenter study. J Psychosom Res (1996) 6:551-9. doi:10.1016/ S0022-3999(96)00228-0

37. Craparo G, Faraci P, Gori A. Psychometric properties of the 20-item Toronto Alexithymia Scale in a group of Italian younger adolescents. Psychiatry Investig (2015) 12:500-7. doi:10.4306/pi.2015.12.4.500

38. Istituto Nazionale di Statistica (ISTAT). Alcohol Consumption in Italy. Rome (2016). Available from: https://www.alcol.net/images/rapporti_ricerca/ Consumo_alcol_in_Italia_2016.pdf 
39. Goncy EA, Mrug S. Where and when adolescents use tobacco, alcohol, and marijuana: comparisons by age, gender, and race. J Stud Alcohol Drugs (2013) 74:288-300. doi:10.15288/jsad.2013.74.288

40. Minutillo A, Pacifici R, Scaravelli G, De Luca R, Palmi I, Mortali C, et al. Gender disparity in addiction: an Italian epidemiological sketch. Ann Ist Super Sanita (2016) 52:176-83. doi:10.4415/ANN_16_02_08

41. Gmel G, Gutjahr E, Rehm J. How stable is the risk curve between alcohol and all-cause mortality and what factors influence the shape? A precision-weighted hierarchical meta-analysis. Eur J Epidemiol (2003) 18:631-42. doi:10.1023/ A:1024805021504

42. Taylor BJ, Shield KD, Rehm JT. Combining best evidence: a novel method to calculate the alcohol-attributable fraction and its variance for injury mortality. BMC Public Health (2011) 11:265. doi:10.1186/1471-2458-11-265

43. Crews FT, Vetreno RP, Broadwater MA, Robinson DL. Adolescent alcohol exposure persistently impacts adult neurobiology and behavior. Pharmacol Rev (2016) 68:1074-109. doi:10.1124/pr.115.012138

44. Kuntsche E, Kuntsche S, Thrul J, Gmel G. Binge drinking: health impact, prevalence, correlates and interventions. Psychol Health (2017) 32:976-1017. doi:10.1080/08870446.2017.1325889

45. Perkins HW, Linkenbach J, Dejong W. Estimated blood alcohol levels reached by "binge" and "nonbinge" drinkers: a survey of young adults in Montana. Psychol Addict Behav (2001) 15:317-20. doi:10.1037/0893-164X.15. 4.317

46. Molinaro S, Siciliano V, Curzio O, Denoth F, Salvadori S, Mariani F. Illegal substance use among Italian high school students: trends over 11 years (1999-2009). PLoS One (2011) 6:e20482. doi:10.1371/journal.pone. 0020482

47. Johnson RM, Fairman B, Gilreath T, Xuan Z, Rothman EF, Parnham T, et al. Past 15-year trends in adolescent marijuana use: differences by race/ethnicity and sex. Drug Alcohol Depend (2015) 1:8-15. doi:10.1016/j.drugalcdep. 2015.08.025

48. Craft RM, Marusich JA, Wiley JL. Sex differences in cannabinoid pharmacology: a reflection of differences in the endocannabinoid system? Life Sci (2013) 92:476-81. doi:10.1016/j.lfs.2012.06.009

49. Kawabe K, Horiuchi F, Ochi M, Oka Y, Ueno S. Internet addiction: prevalence and relation with mental states in adolescents. Psychiatry Clin Neurosci (2016) 70:405-12. doi:10.1111/pcn.12402

50. Durkee T, Kaess M, Carli V, Parzer P, Wasserman C, Floderus B, et al. Prevalence of pathological Internet use among adolescents in Europe: demographic and social factors. Addiction (2012) 107:2210-22. doi:10.1111/j.13600443.2012.03946.x

51. Poli R, Agrimi E. Internet addiction disorder: prevalence in an Italian student population. Nord J Psychiatry (2012) 66:55-9. doi:10.3109/08039488.2011. 605169

52. Kaess M, Parzer P, Brunner R, Koenig J, Durkee T, Carli V, et al. Pathological Internet use is on the rise among European adolescents. J Adolesc Health (2016) 59:236-9. doi:10.1016/j.jadohealth.2016.04.009

53. Calado F, Alexandre J, Griffiths MD. Prevalence of adolescent problem gambling: a systematic review of recent research. J Gambl Stud (2016) 33: 397-424. doi:10.1007/s10899-016-9627-5

54. González-Roz A, Fernández-Hermida JR, Weidberg S, Martínez-Loredo V, Secades-Villa R. Prevalence of problem gambling among adolescents: a comparison across modes of access, gambling activities, and levels of severity. J Gambl Stud (2017) 33:371-82. doi:10.1007/s10899-016-9652-4

55. Meulemans S, Pribis P, Grajales T, Krivak G. Gender differences in exercise dependence and eating disorders in young adults: a path analysis of a conceptual model. Nutrients (2014) 6:4895-905. doi:10.3390/nu6114895

56. Sussman S, Pokhrel P, Sun P, Rohrbach LA, Spruijt-Metz D. Prevalence and co-occurrence of addictive behaviors among former alternative high school youth: a longitudinal follow-up study. J Behav Addict (2015) 4:189-94. doi:10.1556/2006.4.2015.027

57. Mc Cormack A, Shorter GW, Griffiths MD. An empirical study of gender differences in online gambling. J Gambl Stud (2014) 30:71-88. doi:10.1007/ s10899-012-9341-x

58. Henkel D, Zemlin U. Social inequality and substance use and problematic gambling among adolescents and young adults: a review of epidemiological surveys in Germany. Curr Drug Abuse Rev (2016) 9:26-48. doi:10.2174/1874 473709666151209114023
59. Di Nicola M, Tedeschi D, De Risio L, Pettorruso M, Martinotti G, Ruggeri F, et al. Co-occurrence of alcohol use disorder and behavioral addictions: relevance of impulsivity and craving. Drug Alcohol Depend (2015) 148:118-25. doi:10.1016/j.drugalcdep.2014.12.028

60. Luczak SE, Khoddam R, Yu S, Wall TL, Schwartz A, Sussman S. A review of the prevalence and co-occurrence of addictions in US ethnic/racial groups: implications for genetic research. Am J Addict (2017) 26:424-36. doi:10.1111/ ajad.12464

61. Martinotti G, Villella C, Di Thiene D, Di Nicola M, Bria P, Conte G, et al. Problematic mobile phone use in adolescence: a cross-sectional study. J Public Health (2011) 19:545-51. doi:10.1007/s10389-011-0422-6

62. Villella C, Martinotti G, Di Nicola M, Cassano M, La Torre G, Gliubizzi MD, et al. Behavioural addictions in adolescents and young adults: results from a prevalence study. J Gambl Stud (2011) 27:203-14. doi:10.1007/s10899010-9206-0

63. Bibbey A, Phillips AC, Ginty AT, Carroll D. Problematic Internet use, excessive alcohol consumption, their comorbidity and cardiovascular and cortisol reactions to acute psychological stress in a student population. J Behav Addict (2015) 4:44-52. doi:10.1556/2006.4.2015.006

64. Whelan R, Watts R, Orr CA, Althoff RR, Artiges E, Banaschewski T, et al. Neuropsychosocial profiles of current and future adolescent alcohol misusers. Nature (2014) 512:185-9. doi:10.1038/nature13402

65. Gori A, Craparo G, Caretti V, Giannini M, Iraci-Sareri G, Bruschi A, et al. Impulsivity, alexithymia and dissociation among pathological gamblers in different therapeutic settings: a multisample comparison study. Psychiatry Res (2016) 30:789-95. doi:10.1016/j.psychres.2016.10.046

66. De Berardis D, D'Albenzio A, Gambi F, Sepede G, Valchera A, Conti CM, et al. Alexithymia and its relationships with dissociative experiences and Internet addiction in a nonclinical sample. Cyberpsychol Behav (2009) 12:67-9. doi:10.1089/cpb.2008.0108

67. Craparo G. Internet addiction, dissociation and alexithymia. Proced Soc Behav Sci (2011) 30:1051-6. doi:10.1016/j.sbspro.2011.10.205

68. Barnow S, Limberg A, Stopsack M, Spitzer C, Grabe HJ, Freyberger HJ, et al. Dissociation and emotion regulation in borderline personality disorder. Psychol Med (2012) 42:783-94. doi:10.1017/S0033291711001917

69. van der Hart O, Nijenhuis ERS, Steele K. Structural Dissociation and the Treatment of Chronic Traumatization. London: Norton \& Norton Company (2006).

70. Bromberg PM. Shrinking the tsunami: affect regulation, dissociation, and the shadow of the flood. Contemp Psychoanal (2008) 44:329-50. doi:10.1080/ 00107530.2008.10745961

71. Putnam FW. Dissociation in Children and Adolescents: A Developmental Perspective. New York: Guilford Press (1997).

72. Amrhein C, Hengmith S, Maragkos M, Hennig-Fast K. Neuropsychological characteristics of highly dissociative healthy individuals. J Trauma Dissociation (2008) 9:525-42. doi:10.1080/15299730802226332

73. Rossouw TI, Fonagy P. Mentalization-based treatment for self-harm in adolescents: a randomized controlled trial. J Am Acad Child Adolesc Psychiatry (2012) 51:1304-13.e3. doi:10.1016/j.jaac.2012.09.018

74. Khantzian EJ. Addiction as a self-regulation disorder and the role of selfmedication. Addiction (2013) 108:668-9. doi:10.1111/add.12004

75. Taylor GJ, Bagby RM, Parker JDA. Disorders of Affect Regulation: Alexithymia in Medical and Psychiatric Illness. Cambridge: Cambridge University Press (1997).

76. Pokhrel P, Herzog TA, Black DS, Zaman A, Riggs NR, Sussman S. Adolescent neurocognitive development, self-regulation, and school-based drug use prevention. Prev Sci (2013) 14:218-28. doi:10.1007/s11121-0120345-7

77. Cerniglia L, Zoratto F, Cimino S, Laviola G, Ammaniti M, Adriani W. Internet addiction in adolescence: neurobiological, psychosocial and clinical issues. Neurosci Biobehav Rev (2017) 76:174-84. doi:10.1016/j.neubiorev. 2016.12.024

78. Keane H. Disorders of desire: addiction and problems of intimacy. J Med Humanit (2004) 25:189-204. doi:10.1023/B:JOMH.0000036637.03254.38

79. Kardefelt-Winther D, Heeren A, Schimmenti A, van Rooij A, Maurage P, Carras M, et al. How can we conceptualize behavioural addiction without pathologizing common behaviours? Addiction (2017) 112:1709-15. doi:10.1111/ add. 13763 
80. Busch V, Laninga-Wijnen L, Schrijvers AJ, De Leeuw JR. Associations of health behaviors, school performance and psychosocial problems in adolescents in The Netherlands. Health Promot Int (2017) 32:280-91. doi:10.1093/ heapro/dav058

81. Floros G, Paradisioti A, Hadjimarcou M, Mappouras DG, Karkanioti O, Siomos K. Adolescent online gambling in Cyprus: associated school performance and psychopathology. J Gambl Stud (2015) 31:367-84. doi:10.1007/ s10899-013-9424-3

82. Cheng C, Li AY. Internet addiction prevalence and quality of (real) life: a meta-analysis of 31 nations across seven world regions. Cyberpsychol Behav Soc Netw (2014) 17:755-60. doi:10.1089/cyber.2014.0317

83. Lim JA, Gwak AR, Park SM, Kwon JG, Lee JY, Jung HY, et al. Are adolescents with Internet addiction prone to aggressive behavior? The mediating effect of clinical comorbidities on the predictability of aggression in adolescents with Internet addiction. Cyberpsychol Behav Soc Netw (2015) 18:260-7. doi:10.1089/cyber.2014.0568
84. Lee BH, Lee HK. Longitudinal study shows that addictive Internet use during adolescence was associated with heavy drinking and smoking cigarettes in early adulthood. Acta Paediatr (2017) 106:497-502. doi:10.1111/apa.13706

Conflict of Interest Statement: The authors declare that the research was conducted in the absence of any commercial or financial relationships that could be construed as a potential conflict of interest.

Copyright (c) 2017 Di Nicola, Ferri, Moccia, Panaccione, Strangio, Tedeschi, Grandinetti, Callea, De-Giorgio, Martinotti and Janiri. This is an open-access article distributed under the terms of the Creative Commons Attribution License (CC BY). The use, distribution or reproduction in other forums is permitted, provided the original author(s) or licensor are credited and that the original publication in this journal is cited, in accordance with accepted academic practice. No use, distribution or reproduction is permitted which does not comply with these terms. 